\title{
P. H. Hernández, poeta del dolor
}

PREAMBULO

El pueblo puertorriqueño peca de olvidadizo; pero, gracias a la tenacidad de una minoría selecta de intelectuales, los nombres de Hostos, Degetau, Baldorioty, Betances, José de Diego y Gautier Benítez, entre otros, están presentes en la conciencia de la juventud estudiosa del país.

En el 1936 un prupo de jóvenes univèrsitarios hizo realidad sus inquietudes con un cálido homenaje a la memoria de P. H. Hernández. "Hemos tropezado con desengaños y duchas de agua helada...", dice la directiva a cargo del acto. Sin embargo, la plena convicción de espíritu de aquéllos que se habían propuesto "prender fervor por el poeta" logró dar a conocer al lírico de Hatillo, que es motivo de nuestra atención en este trabajo.

EL HOMBRE

\section{Su vida}

El 22 de mayo de 1892 nace José Polonio Hernández y Hernández en Hatillo, pueblecito al norte de Puerto Rico. La más cruel indigencia le rodea desde sus primeros años. Sus padres, de humilde origen, nada pueden of recerle sino un destartalado bohío en que se ha entronizado la miseria. Alli crece el poeta en ciernes, flaco, pálido, enfermizo.

En el 1899, o sea, a principios de la soberanía americana en el país, comienza José Polonio sus estudios en las escuelas elementales que el nuevo régimen establece. Tal parece que la naturaleza, 
que hasta ahora todo se lo ha negado, se propone recompensarlo por sus sufrimientos dotándolo de una clara inteligencia.

Pepito, como cariñosamente lo llaman sus compañeros, es el estudiante más aprovechado del grupo; el más popular también. Lo comprueba la protección que le brindan sus condiscípulos que se disputan el privilegio de llevarlo a su casa a vivir. Gracias a sus amigos Lorán, Antonio David y José Delgado consigue él hospedaje gratis durante el transcurso de su instrucción primaria.

Su espíritu religioso, que vemos manifestarse más tarde en su obra poética, empieza a echar raíces en esos días. Pepito asiste al servicio de la iglesia metodista, lee la Biblia, reflexiona, consulta obras de autores místicos. Más tarde se absorbe en la lectura de tratados filosóficos, teosóficos.

Estudia música bajo la dirección de don Tomás Milián. La influencia que el maestro ejerce sobre él es decisiva. Don Tomás no solamente es un técnico en materia musical sino también un hombre profundamente moral y humanitario. "Hombre de rectos principios, de vida limpia y conciencia sana", dice Angel Melgar. ${ }^{1}$ A pesar de ser un ferviente católico no impide que su protegido asista a la iglesia metodista.

Pepito sorprende al maestro con su progreso en el bombardino. En breve lapso de tiempo domina las dificultades y adquiere habilidad instrumental. Cuando se gradúa de octavo grado ya lo toca admirablemente.

La segunda etapa de su educación es un período de sacrificios consumados a base de voluntad y carácter. Pepito se traslada a San Juan e ingresa en la Escuela Superior Central. Para poder costear sus gastos personales y a la vez enviar a sus padres alguna ayuda toca el bombardino en bailes que se extienden a veces hasta las siete de la mañana. Al salir se lava la cara a la ligera y sin haber desayunado, se apresura hacia la escuela para no llegar tarde a su primera clase. Esto se repite muchas veces. Gracias a la generosidad de los Milián no tiene que preocuparse por el hospedaje. A pesar de las dificultades con que tropieza, Pepito completa sus estudios en tres años y obtiene su diploma con altos honores.

Don Francisco Milián, hermano de don Tomás, le consigue una beca del Departamento de Instrucción. Recibe mensualmente doce dólares, seis de los cuales envía a su casa. 
En una de sus visitas a Hatillo conoce a Carmen Sánchez, linda hija de don Felipe Sánchez Goytia. "Pobre en recursos materiales", dice muy bien Angel Melgar, "no tiene la acogida favorable de don Felipe; rico en recursos espirituales, despierta simpatías en el alma de Carmen y se inicia su primero y único amor." 2

Los ojos de Carmen son fuente de inspiración para su primer poema. Su amor contrariado lo lleva a refugiarse en la composición musical. En todo se refleja el alma lírica del poeta.

Regresa a San Juan a proseguir sus estudios. Lleva los ojos de Carmen prendidos al corazón. Comienza de nuevo la lucha por el ideal. La beca apenas cubre sus gastos personales. Decide pues ingresar en una orquesta de la que se valían las compañías dramáticas extranjeras de paso por San Juan. Estudia con tesón para poder presentarse ante la Junta Examinadora de Estudios Libres que ha de conferirle el título de farmacéutico. Aún le sobra tiempo para dedicarlo a sus lecturas literarias.

Su deseo de saber es verdadero. Ya domina el inglés, el francés, el latín. Aun sabe algo de griego. Desea hacerse médico cirujano y su primer paso es adquirir licencia de cirujano menor.

Como si todo este fardo de trabajos y preocupaciones no fuera suficiente para absorber su vida, Hernández suele asistir de noche a una tertulia literaria en que figuran escritores distinguidos como Luis Llorens Torres, Evaristo Rivera Chevremont, Ferdinand R. Cestero y Nicolás Blanco. Cayetano Coll y Toste se interesa en el joven y trata de orientarlo. Son estos los primeros contactos que tiene él con el munđo literario. Ya en la residencia de don Tomás Milián se ha familiarizado con Felipe Dessus, Carrión Maduro y otros.

En 1912 obtiene su licencia de farmacéutico y acepta un puesto en Corozal. Los padres de Carmen trataron de alejarla de Hatillo pero ella regresa al pucblo después de una estadía en Ponce. Hernández decide establecer una farmacia en su propio pueblo. Las autoridades de Hatillo lo nombran director escolar de música; con un sueldo de cuarenta dólares mensuales. La tenaz oposición del padre de Carmen se debilita. Finalmente da su consentimiento. Los jóvenes contraen matrimonio y fijan su residencia, dos años despttés, en Río Grande. Allí Hernández es cirujano menor y regente 
de la farmacia municipal. Además administra una farmacia que ha arrendado en el pueblo.

Todos le conocen por el cariñoso apodo de "Pepe". Para los pobres, Hernández es a manera de un ángel protector que siembra el bien a manos llenas. Se olvida de sí mismo en su empeño de aliviar las miserias ajenas. En el 1918 una plaga de influenza ataca la isla. Hernánđez substituye al doctor Boneta, que está enfermo. "Deja su casa a las seis de la mañana", dice Angel Melgar, "y si regresa ha de ser a las doce de la noche."

Hernández hace milagros con el tiempo. Su actividad profesional no absorbe toda su vida. Lee mucho, cultiva la poesía y la música $y$ se mantiene en contacto con sus buenos amigos Fernando Torregrosa, José A. Balseiro, Carlos N. Carreras y el padre Rivera.

Su gran ambición de estudiar medicina en los Estados Unidos se malogra, pero él vive feliz rodeado de su mujer y de sus hijos, entregado a sus amados libros.

Un organismo tan débil como el suyo tiene que resentirse ante tan incesante agitación de vida. Cuando comienza a sentirse enfermo se presenta en el Hospital Municipal de Santurce y allí diagnostican su causa de los pulmones. Su esposa lo recluye en el Sanatorio Insular donde permanece durante quince días; después lo lleva a su casa en Río Grande.

La agonía del poeta es dolorosa. El que había vivido años de vicisitudes, bien merecía el premio de una muerte sosegada. Pero la vida se empeña en torturar al poeta que ve la muerte acercarse pausadamente mientras aguijonean su carne crueles dolores.

La morfina alivia un poco su quebranto y le permite dormir. "Yo mismo hago la solución inyectable", le escribe a un amigo, "y para calmarme a veces necesito inyecciones de ocho centigramos. Nada de vicio." 3

Lenitivo a sus dolores físicos y espirituales es la sinceridad de un grupo selecto de amigos como Luis Dalta, Balseiro, el doctor Fernández García, el licenciado Monclova, el padre Rivera, Fernando Torregrosa. Con su aporte, tanto económico como moral, ayudan al poeta a sobrellevar su fardo de tristezas.

La poesía es refugio a su dolor en ese postrer momento de su vida. Grandes dosis de morfina calman la tos y el poeta se aprovecha para dictar a sus amigos sus últimos poemas. El padre Rivera 
recoge muchos de sus labios para completar el volumen El último combate. A otro amigo, o quizás a su mujer, le dicta el Canto a la mujer puertorriqueña, poema laureado en un certamen del casino.

Pero ya en la noche del 2 de abril de 1922, a las 11.30, su cuerpo no puede más y deja escapar el alma del poeta.

Su entierro es sencillo; sin embargo, pocas demostraciones de cariño y simpatía se han presenciado en Río Grande como la que se le tributó al bardo caído.

\section{Su obra}

Los reveses de fortuna ensombrecieron no sólo la vida sino también la obra de P. H. Hernández. Su primer libro de versos, Coplas de la vereda, apareció en 1919. ${ }^{4}$ Es un folleto que consta de 34 poemas. A raíz de la publicación del libro, el Puerto Rico Ilustrado publicó dos interesantísimos artículos críticos de José A. Balseiro y Cesáreo Rosa Nieves.

En el invierno de 1921 se publicó su obra El íltimo combate 5 con un prólogo del padre Rivera.

Como ya expresamos en párrafos anteriores, El último combate lo escribió el poeta en cama. Muchas de las elegías que aparecen en este tomo de 25 poemas, las dictó el poeta a su entrañable amigo el padre Rivera. Este preparó el original para la imprenta.

Ya en El uiltimo combate se menciona la próxima obra del poeta, El páramo de los petreles, que habría de llevar un prólogo del poeta español Villaespesa. Este se llevó a España la única copia de dicha obra, mecanografiada con gran esmero por el padre Rivera. Nada se supo de la suerte de la obra. Para el poeta, así como para la poesía, esa fué pérdida irreparable.

En el 1925 Puerto Rico Ilustrado publica sin la debida autorización de la viuda Cantos de la sierra que contiene un prólogo de Carlos N. Carreras.

Gran parte de la producción del poeta se ha perdido. La viuda posee muchos poemas inéditos; sin embargo, obras laureadas como el Canto a la mujer puertorriqueña y Profética han sufrido mutilaciones lamentables. 


\section{GENERALIZACIONES}

Tan acostumbrados estamos a maravillarnos de las novedades de la mecánica moderna y a imitar lo chabacano y chillón que nos impone la moda, que nos olvidamos de que en las cosas sencillas y humildes creadas por la naturaleza hay gran encanto. Nos mostramos indiferentes ante la voz del poeta que describe su mundo interior; nos aburrimos ante las sonoridades de una inspirada composición musical, y es porque hemos cerrado las puertas de nuestra sensibilidad a lo bello, para aplaudir lo grotesco.

La música y la poesía serán siempre oasis en que se refresque el espíritu de los atormentados. Para Hernández ambas fueron bálsamo de su dolor. Sin ellas la vida le hubiera sido imposible. Por eso su verso es "un rincón de apenumbrado olvido, un escondido refugio de amparadora soledad tonificante."

Claro y sencillo es el verso de Hernández. En él no caben ni el retorcimiento de la frase, ni la fatua retórica de los jactanciosos. Es un verso de diáfana sinceridad en que el poeta expresa sus sentimientos íntimos.

"José P. H. Hernández", ha dicho Manuel Siaca Rivera, "ocupa, por su individualidad vigorosa, por la delicadeza $y$ finura de su sensibilidad y por su dominio de las imágenes, un sitio de honor entre los más destacados poetas de la raza."

Predomina en su poesía la nota de dolor. Su verso saturado de tristeza es queja de un alma atormentada. La vida todo se lo ha negado. En medio de su agonía, no se rebela ante lo inevitable sino que aparece resignado. Los versos en que el poeta destila la retama de su tristeza tienden a difundir la idea de la infelicidad humana. Siente el poeta el deseo de "sembrar en sus lectores la certidumbre de un mal universal, inevitable y absoluto, de cambiarles su fe en duda, su confianza en decepción, su fervoroso celo en helada indiferencia, su cariñosa ilusión en torturante desencanto."

Y ¿para qué luchar? ¿para qué tanto sudor, en nuestra frente? ¿Qué hay al fin de la lucha? $¿$ Laureles de victoria, qué son ante la tumba? 
La vida rota del poeta "sin mañana, sin hoy" nada le ofrece. Su espíritu pesimista sólo ve fatalidad en derredor. Las cosas bellas le oprimen el corazón y le hacen exclamar:

¡Qué sol tan triste! ¿Qué tarde fría!

Campo amarillo de oro mortal.

Todo es pesado. Todo es cansino

¡Qué tarde buena para llorar!

$Y$ en mañanas alegres de primavera, cuando todo parece reír, el dolor ensombrece su espíritu y le hace exhalar una queja:

Duice mañana rosada, mañana de primavera.

¡Oh, qué mañana tan triste para aquel que nada espera!

La obra poética de Hernández es confesión lírica de su vida deshecha. Sus versos reflejan el alma melancólica del poeta vencido. El sabe que la vida se le escapa y se refugia resignado en la soledad para cantar su dolor. La soledad y el silencio, lenitivo de sus penas, se convierten en temas favoritos del poeta:

Soledad que floreciste con rocío de mis penas, estoy triste.

$\mathrm{Y}$ a refrescar mi garganta

vengo a tus ondas serenas.

En el silencio teje sus sueños de gloria, pero también parece pensat en su vida amargada hundiéndose, como dice él mismo, en "el profundo silencio de mis ayeres" que es la muerte:

Silencio que te has dormido sobre el valle, como un leve suspiro de mansedumbre: duerme tu sueño solemne que pronto ha de despertarte - como una alondra dolienteel clamor hondo y amargo -en marejada perennede otro silencio: ¡ el profundo silencio de mis ayeres! 
$Y$ cuando piensa en la idea de hundirse en ese silencio de los silencios se queja de la huidiza gloria, que nunca tocó a sus puertas y teme que ella llegue muy tarde:

$$
\begin{aligned}
& \text { Ha de venir, ¿quién lo duda? } \\
& \text { Pero entonces ¿ para qué? } \\
& \text { Si no habrá luz en mis ojos } \\
& \text { para su hermosura ver... } \\
& \text { y se acercará a mi tumba, } \\
& \text { pero entonces ¿para qué? } \\
& \text { ¿Para qué vendrá a mi tumba? } \\
& \text { ¿Para qué?... }
\end{aligned}
$$

La idea de la muerte es obsesión para el poeta. Su vida tronchada en plena juventud por la tisis, se le escapa lentamente. El siente los pasos de la muerte y ve desvanecerse los sueños de amor y gloria que había acariciado. Vive el poeta sus últimos días en íntima comunión con la muerte. "El la sentía latir siempre cerca de su corazón; conocía sus caricias frías y sus zarpazos implacables. Pero este buen poeta quería vivir a pesar de todo; sabía que la muerte era ya inevitable, que estaba aguardándole en todas las encrucijadas del corto camino de su vida, sin embargo, se aferraba tenazmente a la pobre vida dolorosa que él sabía ya imposible." 6

La muerte parece estar presente en todo lo que le rodea. Tan pronto la ve en los hilos de sangre que recoge su pañuelo en un acceso de tos:

\author{
Rojo hilo, rojo hilo, \\ ¿por qué a mis ojos te muestras? \\ Guárdate oculto, bien hondo \\ sin que mis ojos te vean. \\ ¿Por qué vientes cuando alegre \\ el alma mía se encuentra? \\ ¿Por qué vienes a avisarme \\ que el día ése, está cerca? \\ ¿Por qué vienes, rojo hilo, \\ cuando el alma nía se encuentra \\ saciando un triste mendrugo \\ de alegría pasajera?
}


como la ve en los ojos sin luz de un Cristo crucificado:

\author{
Penetré en tus ojos \\ Y en tu corazón... \\ $\mathrm{Y}$ tus ojos eran \\ vasto cementerio \\ cuajado de tumbas, \\ $Y$ en una de ellas, \\ la más pobre acaso, \\ me encontraba yo. \\ Ni un alma piadosa \\ decía una oración \\ ante aquella tumba \\ donde estaba yo.
}

Obsérvese cómo combina el poeta el tema de la muerte con el de la soledad. Tal parece que lo que le aterra de la muerte no es otra cosa que el olvido en que ha de hundirse y la desilusión de no haber podido calmar su sed de infinito.

Oh, quietud infinita del hondo desconsuelo

que te envuelve, alma mía, como una ola inmensa!

¡Oh, la sed insanciable de tu luz lejanía!

¡Oh, la esperanza última! ¡Oh, la primera estrella!

La naturaleza está presente en toda la obra del poeta. Cuando canta al mar, al cielo, a la luna, al ruiseñor, no se dirige a ellos en particular sino a Dios. Hernández ve en todos los detalles de la obra universal la mano del Todopoderoso.

\footnotetext{
Bajó Dios de los cielos una noche en que la clara luna dormitaba sobre un lecho de lirios. En el broche de cada lirio, un ángel se ocultaba. Era unc apoteosis de biancuras que a le tierra bajaba desde el ciclo y ascentía de lin tierta a las alturas como tura garea en infinito vuelo.

Amasa Dius los ángeles y lirios y de ur. divino cáliz de delirios la mariavilla de tu rostro asoma. Ar' illa una paloma en la arboleda, la toma Dios con su piedad de seda, $y$ te pone por alma una paloma.
} 
Como un gran poeta, Hernández cantó a una mujer. E1 amor a esa mujer le sirvió de fuente inagotable le inspiración. Hernández madrigalista se revela en su muy conocida composición "Ojos astrales", madrigal que nada tiene que envidiar al de Cetina:

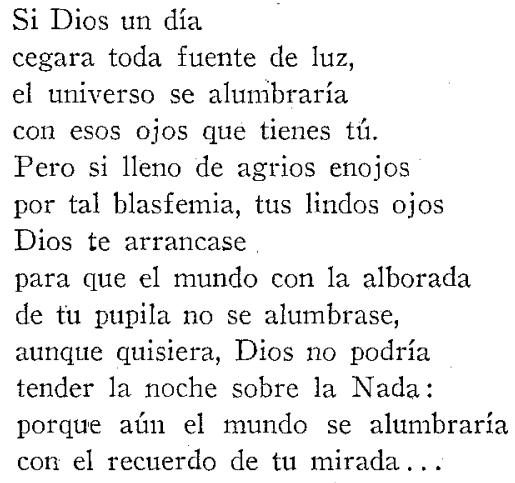

Raro es que un ferviente religioso como P. H. Hernández se deje arrastrar por su entusiasmo poético para expresar una blasfemia como ésta; sin embargo, esto demuestra la sinceridad y legítima inspiración del poeta que "en medio de su conturbación espiritual" no responde a otra cosa que a la emoción que le produce la belleza en ese momento.

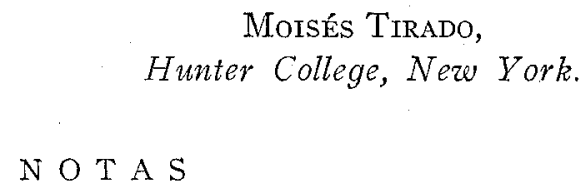

Moisés Tirado, Hunter College, New York.$$
\text { N O T A S }
$$

1 Angel Melgar. "Intento crítico, biográfico, Peache". Alma Latina, San Juan, P. R., mayo, 1936, p. 21.

2 Idem., p. 22.

3 Idem., p. 24.

4 Impreso en la Standard Printing Work, San Juan, P R., prólogo de Luis Dalta.

5 Publicado por La Democracia, Inc,, invierno 1921, prólogo del padre Rivera.

6 Washington Llorens. "Críticas profanas". Alma Latina, San Juan, P. R., mayo, 1936, p. 21. 